\title{
Optimization of magnetocaloric properties of arc-melted and spark plasma-sintered $\mathrm{LaFe}_{11.6} \mathrm{Si}_{1.4}$
}

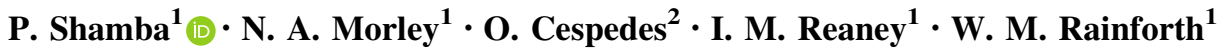

Received: 7 April 2016/Accepted: 2 July 2016/Published online: 12 July 2016

(C) The Author(s) 2016. This article is published with open access at Springerlink.com

\begin{abstract}
LaFe}_{11.6} \mathrm{Si}_{1.4}$ alloy has been synthesized in polycrystalline form using both arc melting and spark plasma sintering (SPS). The phase formation, hysteresis loss and magnetocaloric properties of the $\mathrm{LaFe}_{11.6} \mathrm{Si}_{1.4}$ alloys synthesized using the two different techniques are compared. The annealing time required to obtain the 1:13 phase is significantly reduced from 14 days (using the arc melting technique) to $30 \mathrm{~min}$ (using the SPS technique). The magnetic entropy change $\left(\Delta S_{\mathrm{M}}\right)$ for the arc-melted $\mathrm{LaFe}_{11.6} \mathrm{Si}_{1.4}$ compound, obtained for a field change of $5-0 T$ (decreasing field), was estimated to be $19.6 \mathrm{~J} \mathrm{~kg}^{-1} \mathrm{~K}^{-1}$. The effective RCP at $5 T$ of the arc-melted $\mathrm{LaFe}_{11.6} \mathrm{Si}_{1.4}$ compound was determined to be $360 \mathrm{~J} \mathrm{~kg}^{-1}$ which corresponds to about $88 \%$ of that observed in Gd. A significant reduction in the hysteretic losses in the SPS $\mathrm{LaFe}_{11.6} \mathrm{Si}_{1.4}$ compound was observed. The $\Delta S_{\mathrm{M}}$, obtained for a field change of $5-0 T$ (decreasing field), for the SPS LaFe 11.6 $_{1.4} \mathrm{Si}_{1.4}$ compound decreases to $7.4 \mathrm{~J} \mathrm{~kg}^{-1} \mathrm{~K}^{-1}$. The $T_{\mathrm{C}}$ also shifts from 186 (arc-melted) to $230 \mathrm{~K}$ (SPS) and shifts the order of phase transition from first to second order, respectively. The MCE of the SPS $\mathrm{LaFe}_{11.6} \mathrm{Si}_{1.4}$ compound spreads over a larger temperature range with the RCP value at $5 T$ reaching $288 \mathrm{~J} \mathrm{~kg}^{-1}$ corresponding to about $70 \%$ of that observed in Gd. At low fields, the effective RCP values of the arc-melted and spark plasma-sintered $\mathrm{LaFe}_{11.6} \mathrm{Si}_{1.4}$ compounds are comparable, thereby clearly demonstrating the potential of SPS $\mathrm{LaFe}_{11.6} \mathrm{Si}_{1.4}$ compounds in low-field magnetic refrigeration applications.
\end{abstract}

\section{P. Shamba \\ p.shamba@sheffield.ac.uk}

1 Department of Materials Science and Engineering, University of Sheffield, Sheffield S1 3JD, UK

2 School of Physics and Astronomy, University of Leeds, Leeds LS2 9JT, UK

\section{Introduction}

Conventional refrigeration technologies based on the gascompression/expansion cooling mechanisms may gradually be replaced by the environmentally friendly and more efficient magnetic refrigeration in the near future [1-5]. Magnetic refrigeration is based on the magnetocaloric effect (MCE) which results from the coupling of a system of magnetic moments with an external magnetic field resulting in the cooling or heating of a system. Recently, a new class of magnetic materials has emerged, called giant magnetocaloric effect (GMCE) materials, which undergo a phase transition from one form of magnetic order to another with an associated "giant" change in entropy. The $\mathrm{La}\left(\mathrm{Fe}_{\mathrm{x}} \mathrm{Si}_{1-\mathrm{x}}\right)_{13}$ material system belongs to this GMCE group of materials. It also has an added advantage of consisting of low-cost elements. The only drawback of this material system, however, is the problem of low productivity in manufacturing $\mathrm{La}\left(\mathrm{Fe}_{\mathrm{x}} \mathrm{Si}_{1-\mathrm{x}}\right)_{13}$-type materials. The $\mathrm{NaZn}_{13}$ phase is rarely directly generated in ingots prepared by conventional methods such as arc melting due to an incomplete peritectic reaction which results in the mixed phases of $\boldsymbol{\alpha}-\mathrm{Fe}+\mathrm{La}(\mathrm{Fe}, \mathrm{Si})_{13}\left(\tau_{1 \mathrm{a}}\right)+\operatorname{LaFeSi}\left(\tau_{4}\right)$ [6]. Accordingly, a long annealing time (typically 14-30 days) is necessary to form the $\mathrm{NaZn}_{13}$ structure. Therefore, it is imperative to find a quicker and cheaper way of synthesizing these alloys, promoting the affordability of the $\mathrm{La}\left(\mathrm{Fe}_{\mathrm{x}} \mathrm{Si}_{1-\mathrm{x}}\right)_{13}$-based magnetic refrigerators.

This work seeks to explore the synthesis of the $\mathrm{La}\left(\mathrm{Fe}_{\mathrm{x}} \mathrm{Si}_{1-\mathrm{x}}\right)_{13}$-type materials using the spark plasma sintering (SPS) technique. In the spark plasma sintering technique, the powders are heated by the joule effect and the spark which is generated in the spaces between the powder particles activates the surface of these particles generating a self-heating approach which leads to 
significantly shorter sintering times required and results in fine grain structures [7]. Compared to arc melting, the SPS technique occurs at relatively low average temperatures and is completed in shorter periods of time resulting in a tight control over grain growth and microstructure [8]. Due to the above-mentioned reasons, we expect the $\mathrm{La}\left(\mathrm{Fe}_{\mathrm{x}}\right.$ $\left.\mathrm{Si}_{1-\mathrm{x}}\right)_{13}$ alloys prepared by SPS to require significantly shorter heat treatment times for obtaining the cubic $\mathrm{NaZn}_{13}$ crystal structure-type phase. Shorter heat treatment times will significantly reduce the cost of synthesizing the $\mathrm{La}\left(\mathrm{Fe}_{\mathrm{x}} \mathrm{Si}_{1-\mathrm{x}}\right)_{13}$ alloys which in turn have a positive impact on the affordability of $\mathrm{La}\left(\mathrm{Fe}_{\mathrm{x}} \mathrm{Si}_{1-\mathrm{x}}\right)_{13}$-based magnetic refrigerators. Also, we expect the resulting microstructure in SPS $\mathrm{La}\left(\mathrm{Fe}_{\mathrm{x}} \mathrm{Si}_{1-\mathrm{x}}\right)_{13}$ to influence the magnetic hysteresis in this material system, similar to what was observed by Idza et al. [9] for the polycrystalline nickel-zinc ferrite $\mathrm{Ni}_{0.3} \mathrm{Zn}_{0.7} \mathrm{Fe}_{2} \mathrm{O}_{4}$ [9]. If indeed the magnetic hysteresis is significantly reduced in the SPS $\mathrm{La}\left(\mathrm{Fe}_{\mathrm{x}} \mathrm{Si}_{1-\mathrm{x}}\right)_{13}$, this will consequently improve its magnetocaloric properties.

In this work, the effect of a solid-state reaction using the spark plasma sintering (SPS) technique to form the $\mathrm{NaZn}_{13}$ structure is investigated and compared with the conventional arc melting method. The SPS synthesis of $\mathrm{LaFe}_{11.6} \mathrm{Si}_{1.4}$ has been investigated for a range of sintering conditions such as temperature, pressure, and holding time. We then performed a heat treatment study to optimize the 1:13 phase yield in the SPS $\mathrm{LaFe}_{11.6} \mathrm{Si}_{1.4}$. Previously, $\mathrm{LaFe}_{11.6} \mathrm{Si}_{1.4}$ has been synthesized using the SPS technique but to date, there has been one report on the magnetocaloric properties of SPS synthesized $\mathrm{La}\left(\mathrm{Fe}_{\mathrm{x}} \mathrm{Si}_{1-\mathrm{x}}\right)_{13}$ alloys $[10,11]$. The results reported here will make a significant contribution in demonstrating the potential of SPS $\mathrm{La}\left(\mathrm{Fe}_{\mathrm{x}} \mathrm{Si}_{1-\mathrm{x}}\right)_{13}$ alloys for magnetic refrigeration applications making use of permanent magnets.

\section{Experimental procedure}

Two methods were used for the synthesis of the $\mathrm{LaFe}_{11.6}$ $\mathrm{Si}_{1.4}$ compounds. In the first method, the alloy was prepared by arc melting (Arc Melter AM/0.5, Edmund Bühler $\mathrm{GmbH}$ ) appropriate amounts of the high-purity constituent elements under a high-purity argon atmosphere in watercooled copper crucible. The purities of the starting materials were $99.9 \%$ for $\mathrm{La}, 99.95 \%$ for $\mathrm{Si}$, and $99.98 \%$ for Fe. 10 at\% excess La was used to compensate for the weight loss during the arc melting. The ingots were remelted five times to ensure homogeneity. After that, the resulting ingots were wrapped in tantalum foil, annealed at $1323 \mathrm{~K}$ for 14 days in an evacuated quartz tube and then quenched in water in order to obtain the $\mathrm{NaZn}_{13}$-type main phase. The second method used was spark plasma sintering technique to synthesize the $\mathrm{LaFe}_{11.6} \mathrm{Si}_{1.4}$ compound. In this method, metal powders of $\mathrm{La}, \mathrm{Fe}$, and $\mathrm{Si}$ with purities higher than $99.9 \%$ and particle sizes shown in Table 1 were used as starting materials. Five grams of the powders in the required stoichiometric ratio was mixed thoroughly using a speedmixer (Speedmixer DAC 800 FVZ). The powders were then consolidated by spark plasma sintering (FCT Systeme GmBH SPS system, type HPD 1050, Germany) in a 20-mm graphite die under argon atmosphere. The conditions for sintering are shown in Table 1.

The SPS device automatically recorded the processing conditions during the SPS process as shown in Fig. 1. Figure 1 shows the variation in the applied force, temperature, power limit, and axial displacement during a typical sintering run. It is observed that during the dwell time, the aforementioned parameters remained constant as expected.

The resulting $\mathrm{LaFe}_{11.6} \mathrm{Si}_{1.4}$ pellets were ground, polished, and wrapped in tantalum foil, annealed at 1373-1523 $\mathrm{K}$ for $30 \mathrm{~min}$ to $72 \mathrm{~h}$ in an evacuated quartz tube and then quenched in water in order to obtain the $\mathrm{NaZn}_{13}$-type main phase. The structure was determined using room-temperature powder X-ray diffraction (XRD) with $\mathrm{Cu} \mathrm{K}_{\alpha}$ radiation. The microstructures of the spark plasma-sintered and arc-melted $\mathrm{LaFe}_{11.6} \mathrm{Si}_{1.4}$ alloys were investigated using an FEI Inspect $\mathrm{F}$ (FEI, Netherlands) scanning electron microscope (SEM). The magnetization measurements were taken using the vibration sample magnetometer option of a Quantum Design $6 T$ MPMS SQUID VSM system in the temperature range of $150-300 \mathrm{~K}$ at applied fields of up to $5 T$.

\section{Results and discussion}

Figure 2 shows the XRD patterns of the arc-melted and spark plasma-sintered $\mathrm{LaFe}_{11.6} \mathrm{Si}_{1.4}$ compounds. The XRD pattern of the arc-melted $\mathrm{LaFe}_{11.6} \mathrm{Si}_{1.4}$ alloy (blue pattern)

Table 1 Spark plasma sintering and annealing conditions for spark plasma-sintered $\mathrm{LaFe}_{11.6} \mathrm{Si}_{1.4}$ alloys

\begin{tabular}{lllllcc}
\hline Sample & $\begin{array}{l}\text { Particle size of starting } \\
\text { powders }(\mu \mathrm{m})\end{array}$ & $\begin{array}{l}\text { Applied pressure } \\
(\mathrm{MPa})\end{array}$ & $\begin{array}{l}\text { Holding time } \\
(\mathrm{min})\end{array}$ & $\begin{array}{l}\text { Holding } \\
\text { temp }(\mathrm{K})\end{array}$ & $\begin{array}{l}\text { Annealing } \\
\text { temp }(\mathrm{K})\end{array}$ & $\begin{array}{l}\text { Annealing } \\
\text { time }(\mathrm{h})\end{array}$ \\
\hline Sample 1 & $45-800$ & 41 & 5 & 1423 & 1373 \\
Sample 2 & $45-800$ & 41 & 5 & 1423 & 1473 \\
Sample 3 & $45-74$ & 41 & 5 & 1423 & 1523 \\
Sample 4 & $45-74$ & 41 & 5 & 1423 & 1473 \\
\hline
\end{tabular}



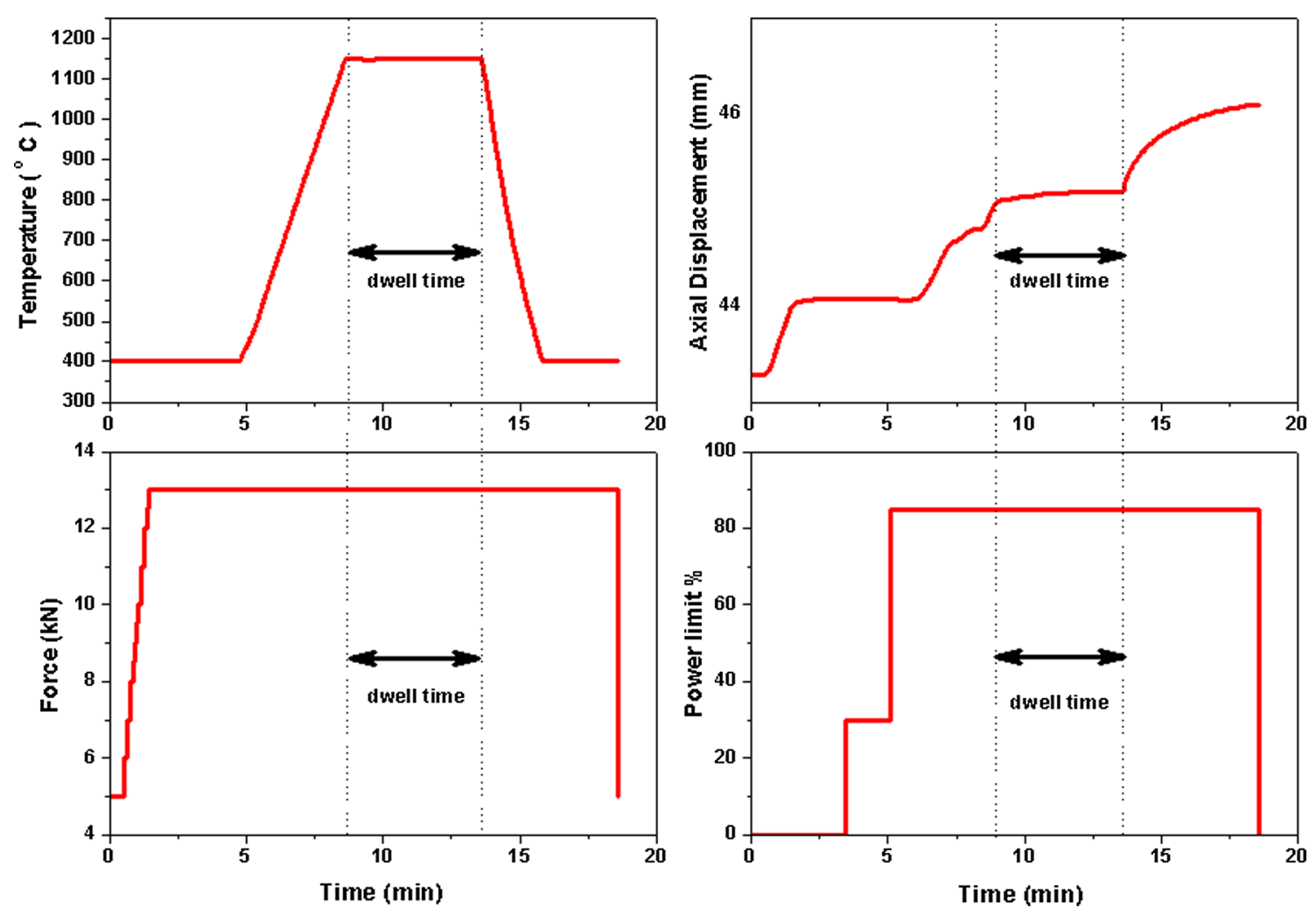

Fig. 1 Applied force, temperature, power limit, and axial displacement profiles during a typical SPS process

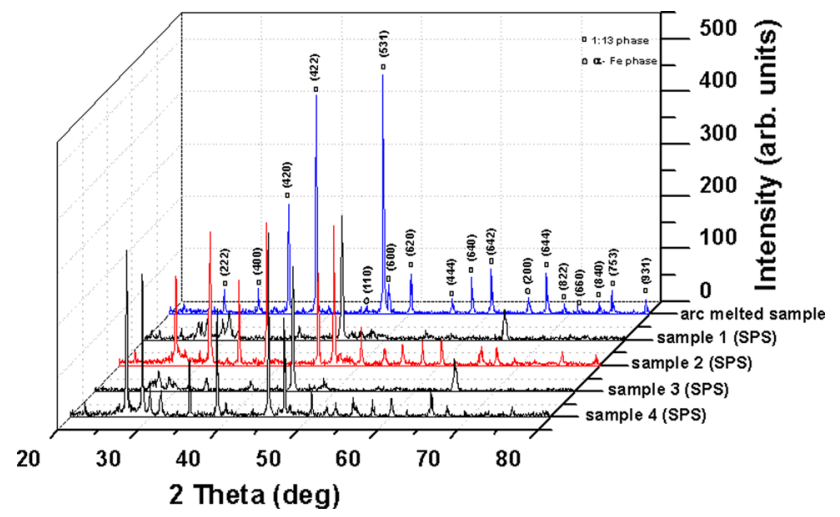

Fig. 2 XRD patterns of the arc-melted (blue pattern) and spark plasma-sintered (red and black patterns) $\mathrm{LaFe}_{11.6} \mathrm{Si}_{1.4}$ alloys. The red XRD pattern is for the optimized SPS $\mathrm{LaFe}_{11.6} \mathrm{Si}_{1.4}$ alloy

indicates that this sample consists mainly of the $\mathrm{NaZn}_{13^{-}}$ type phase and a minor $\alpha$-Fe phase. For the spark plasmasintered samples, however, the XRD patterns for samples 1 and 3 consist mainly of the $\alpha$-Fe phase with a minor amount of the $\mathrm{NaZn}_{13}$-type phase. For sample 4, a significant amount of the $\mathrm{NaZn}_{13}$-type phase is observed; however, the main phase is still the $\alpha$-Fe phase. The optimized SPS $\mathrm{LaFe}_{11.6} \mathrm{Si}_{1.4}$ alloy, sample 2 (red pattern) consists mainly of the $\mathrm{NaZn}_{13}$-type phase with a significant amount of the $\alpha$-Fe phase. In addition to the spark plasma-sintered samples shown in Fig. 2, we have also prepared several other spark plasma-sintered samples which are not shown here for the purposes of clarity. We have performed a comprehensive annealing study of 10 spark plasma-sintered $\mathrm{LaFe}_{11.6} \mathrm{Si}_{1.4}$ samples, varying the annealing temperature as well as the annealing times from 1373 to $1523 \mathrm{~K}$ and $30 \mathrm{~min}$ to $72 \mathrm{~h}$, respectively. This annealing study has consistently shown that $\mathrm{LaFe}_{11.6} \mathrm{Si}_{1.4}$ samples annealed at $1473 \mathrm{~K}$ (for varying annealing times of between $30 \mathrm{~min}$ and $6 \mathrm{~h}$ ) have a significant amount of the $\mathrm{NaZn}_{13}$-type phase compared to samples annealed at other temperatures (for varying annealing times of between $30 \mathrm{~min}$ and $72 \mathrm{~h}$ ). Therefore, this shows that annealing the spark plasma-sintered $\mathrm{LaFe}_{11.6} \mathrm{Si}_{1.4}$ compounds at $1473 \mathrm{~K}$ enhances the formation of the $\mathrm{NaZn}_{13}$-type phase. It also worth mentioning that the significantly different phase compositions of samples 2 and 4 can be attributed to the different particle sizes of the starting powders (shown in Table 1) used for the synthesis of these 2 samples. Sample 2 which was synthesized using the larger-sized lanthanum powder particles $(800 \mu \mathrm{m})$ exhibited a significantly higher amount of the $\mathrm{NaZn}_{13}$-type phase compared to sample 4 which was synthesized using the smaller-sized lanthanum powder particles $(74 \mu \mathrm{m})$. Henceforth, the optimized SPS $\mathrm{LaFe}_{11.6} \mathrm{Si}_{1.4}$ compound, sample 2, will be referred to as the spark plasma-sintered sample in the ensuing paragraphs. 
The grain size of the arc-melted and the spark plasmasintered samples was determined from the XRD using the Scherrer equation and was found to be 44 and $41 \mathrm{~nm}$, respectively, which is similar to what Patissier et al. [11] observed for the spark plasma-sintered sample sintered at $1473 \mathrm{~K}$.

Figure 3 shows the backscattered SEM micrographs of the arc-melted and spark plasma-sintered $\mathrm{LaFe}_{11.6} \mathrm{Si}_{1.4}$ alloys. Both samples were observed in the unpolished condition. The different phases in these alloys were identified by EDS analysis. The arc-melted $\mathrm{LaFe}_{11.6} \mathrm{Si}_{1.4}$ alloy, shown in Fig. 3a, mainly consists of two phases, the phase with lighter gray contrast (1:13 phase) and the phase with darker contrast ( $\alpha$-Fe phase). The arc-melted $\mathrm{LaFe}_{11.6} \mathrm{Si}_{1.4}$ alloy achieved full densification. The SPS $\mathrm{LaFe}_{11.6} \mathrm{Si}_{1.4}$ alloy, shown in Fig. 2b, has a texture with grains of various diameters. The main phase is the 1:13 phase, whilst there is a significant amount of an oxide present (bright contrast phase). This oxide, however, is thought to have accumulated on the sample over time as it was not present when the XRD analysis was performed on the sample.

Figure 4 shows the temperature dependence of the magnetization for the arc-melted and spark plasma-sintered $\mathrm{LaFe}_{11.6} \mathrm{Si}_{1.4}$ compounds measured in the zero-field-cooled (ZFC) and field-cooled (FC) processes under a magnetic field of $200 \mathrm{Oe}$ and a temperature range from 150 to 300 and $0-350 \mathrm{~K}$, respectively. The Curie temperature, $T_{\mathrm{C}}$, which is defined as the temperature at which the $\mathrm{d} M / \mathrm{d} T$ of the heating $M-T$ curves is a minimum, is found to 186 and $230 \mathrm{~K}$ for the arc-melted and spark plasma-sintered $\mathrm{LaFe}_{11.6} \mathrm{Si}_{1.4}$ compounds, respectively (shown in inserts). The $M-T$ curves for the arc-melted $\mathrm{LaFe}_{11.6} \mathrm{Si}_{1.4}$ compound show a sharp ferromagnetic-paramagnetic (FM-PM) transition with a thermal hysteresis of $4.7 \mathrm{~K}$, whereas the spark plasma-sintered $\mathrm{LaFe}_{11.6} \mathrm{Si}_{1.4}$ compound shows a broadened FM-PM transition with no thermal hysteresis. The broadening of the $M-$ $T$ curve is an indication of either a weakened first-order or second-order magnetic transition of this compound. Also, the $M-T$ curve of the spark plasma-sintered $\mathrm{LaFe}_{11.6} \mathrm{Si}_{1.4}$ compound shows the presence of the $\alpha$-Fe impurity phase which is confirmed by a residual magnetization of about $4.5 \mathrm{emu} / \mathrm{g}$ that is left after the phase transition.

Figure 5 shows the magnetization isotherms of the arcmelted and spark plasma-sintered $\mathrm{LaFe}_{11.6} \mathrm{Si}_{1.4}$ compounds, measured in both increasing and decreasing fields over a wide temperature range in the vicinity of $T_{\mathrm{C}}$, with different temperature steps. Arrows indicate the increasing and decreasing magnetic field processes. The sweep rate of the field is slow enough to ensure that the $M-H$ curves are recorded in an isothermal process. The magnetization curves for the arc-melted $\mathrm{LaFe}_{11.6} \mathrm{Si}_{1.4}$ compound shows a magnetic field-induced metamagnetic transition, which will be described in detail below. It is interesting to note that for
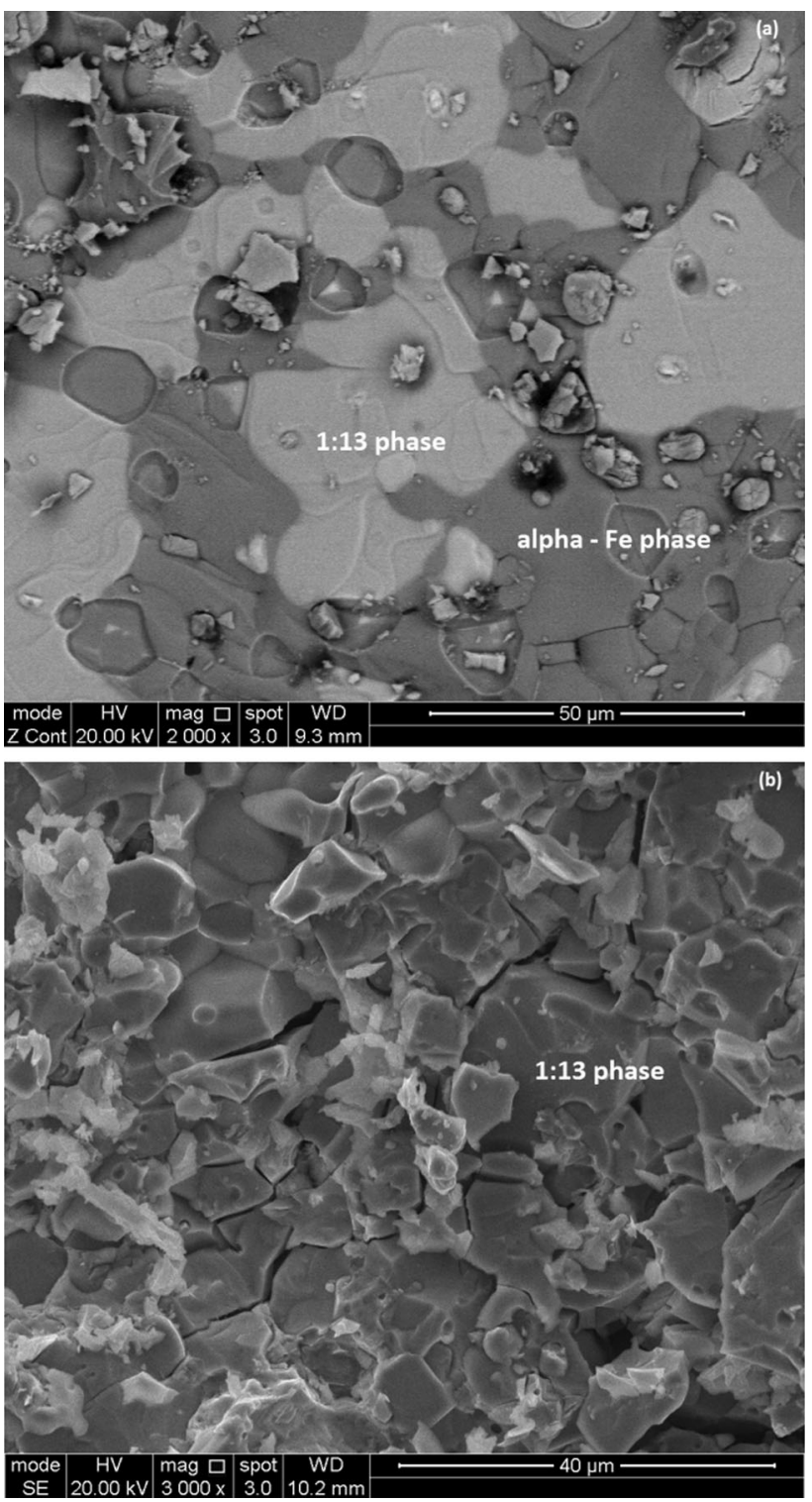

Fig. 3 Backscattered SEM micrographs of $\mathbf{a}$ arc-melted and $\mathbf{b}$ optimized spark plasma-sintered $\mathrm{LaFe}_{11.6} \mathrm{Si}_{1.4}$ alloys

the arc-melted $\mathrm{LaFe}_{11.6} \mathrm{Si}_{1.4}$ compound, around its Curie temperature, it exhibits $\mathrm{S}$-shaped magnetization, which is typical for metamagnetic materials [12]. Also of interest is the observed magnetic irreversibility which manifests itself as a large magnetic hysteresis in the $M-H$ curves for the arc-melted $\mathrm{LaFe}_{11.6} \mathrm{Si}_{1.4}$ compound. This magnetic hysteresis confirms the first-order nature of the magnetic transition of the arc-melted $\mathrm{LaFe}_{11.6} \mathrm{Si}_{1.4}$ compound. In the vicinity of $T_{\mathrm{C}}$ of the spark plasma-sintered $\mathrm{LaFe}_{11.6} \mathrm{Si}_{1.4}$ compound, no metamagnetic behavior is observed confirming the second-order nature of the magnetic phase transition of this compound.

In order to gain a better understanding of the nature of the magnetic phase transition of the arc-melted and spark 


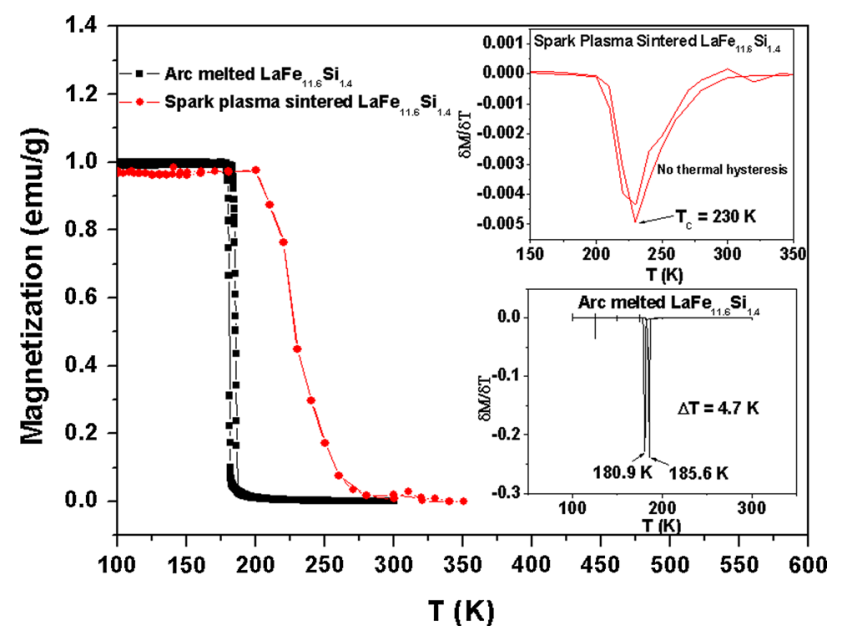

Fig. 4 Temperature dependence of magnetization for the arc-melted and spark plasma-sintered $\mathrm{LaFe}_{11.6} \mathrm{Si}_{1.4}$ compounds measured in a magnetic field of $H=0.02 T$. The inset shows the variation of $\delta M / \delta T$ with temperature plasma-sintered $\mathrm{LaFe}_{11.6} \mathrm{Si}_{1.4}$ compounds, Arrott plots, Fig. 6, were used to determine the type of phase transition of the sample near $T_{C}$ according to the Inoue-Shimizu model [13]. In this model, the free energy $(F)$ of a magnetic system is expressed by the Landau expansion in powers of magnetization, $M$ shown in Eq. (1) below:

$F(M, T)=\frac{1}{2} c_{1}(T) M^{2}+\frac{1}{4} c_{3}(T) M^{4}+\frac{1}{6} c_{5}(T) M^{6}-M H$

The type of transition is related to the sign of the Landau coefficient $c_{3}(T)$ at the Curie temperature $\left[c_{3}\left(T_{\mathrm{C}}\right)\right]$. The sign of $c_{3}\left(T_{\mathrm{C}}\right)$ can be obtained from the Arrott plots. If there are $S$-shaped curves near $T_{\mathrm{C}}$ in the Arrott plots, $c_{3}$ $\left(T_{\mathrm{C}}\right)$ is negative, and hence, the transition is first order; otherwise, it is positive, and the transition is second order. As seen in Fig. 6, the arc-melted $\mathrm{LaFe}_{11.6} \mathrm{Si}_{1.4}$ compound near its $T_{\mathrm{C}}$ exhibits $S$-shaped curves with negative slopes.
Fig. 5 Magnetization isotherms of the arc-melted and spark plasma-sintered $\mathrm{LaFe}_{11.6} \mathrm{Si}_{1.4}$ compounds measured in the field ascending and the field descending processes in a range of temperatures around $T_{\mathrm{C}}$
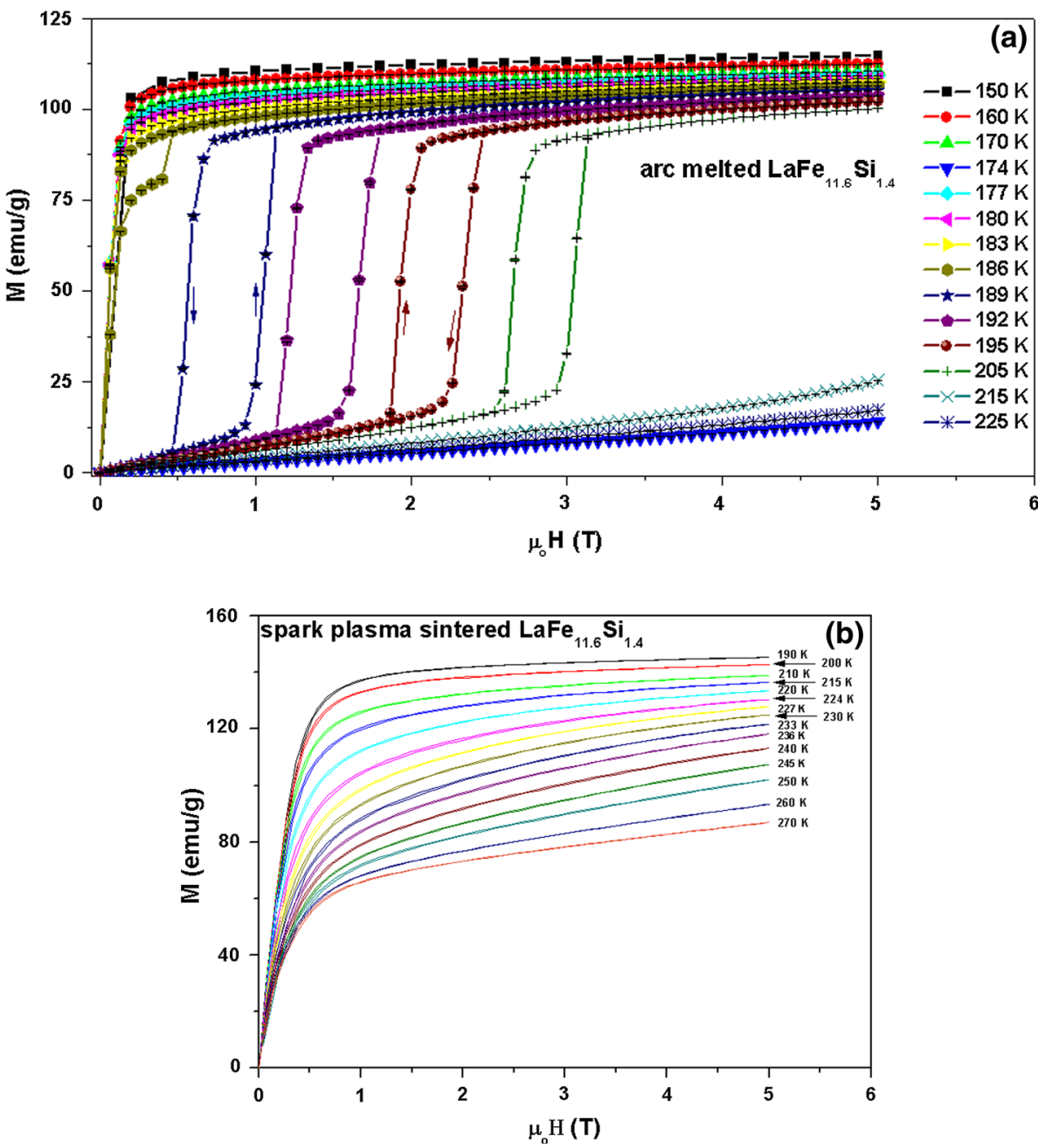

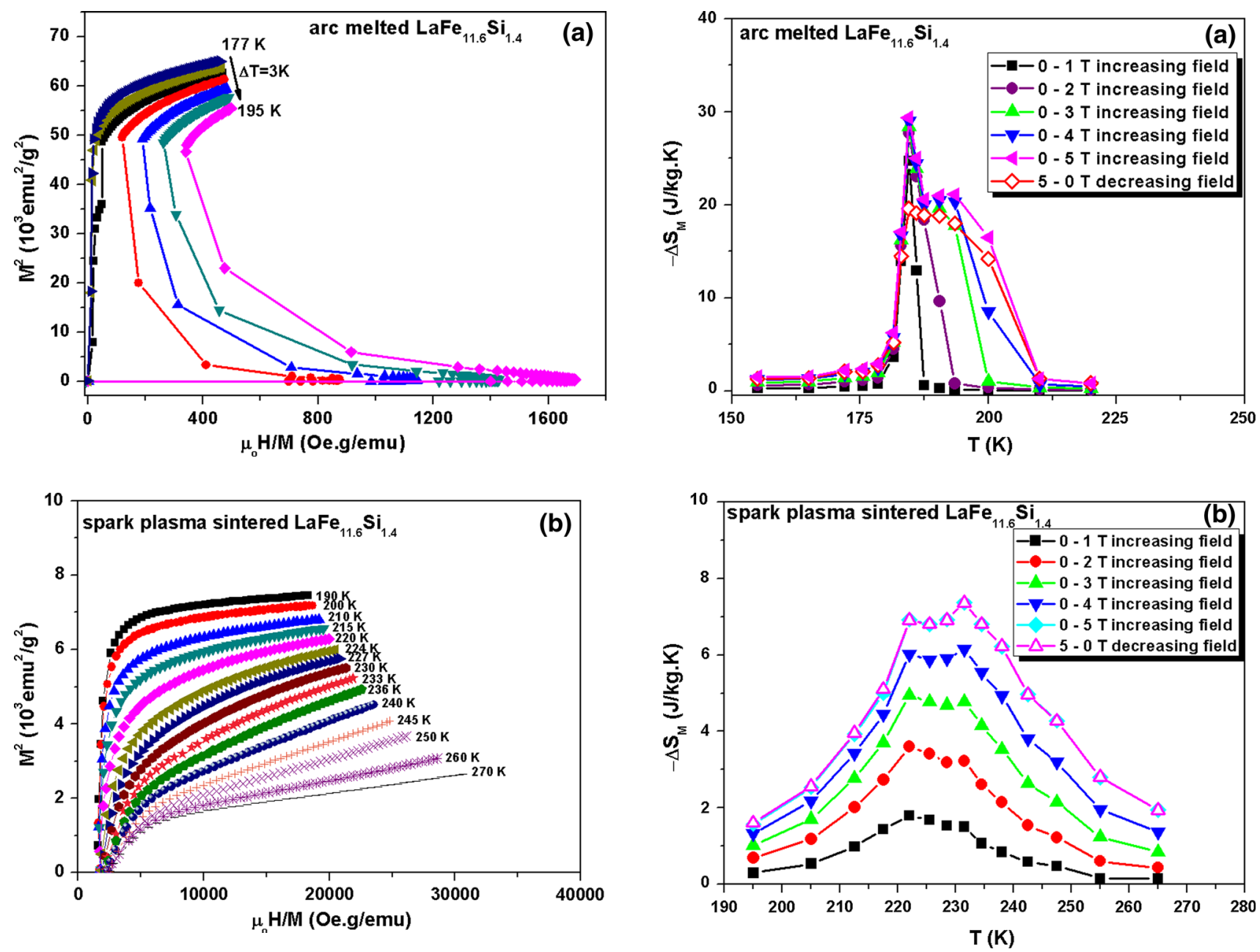

Fig. 6 Arrott plots of isotherms in the vicinity of $T_{\mathrm{C}}$ of arc-melted and spark plasma-sintered $\mathrm{LaFe}_{11.6} \mathrm{Si}_{1.4}$ compounds

These negative slopes confirm the occurrence of metamagnetic transitions from FM to PM state above $T_{\mathrm{C}}$, indicating that the arc-melted $\mathrm{LaFe}_{11.6} \mathrm{Si}_{1.4}$ compound undergoes a first-order transition. For the spark plasmasintered $\mathrm{LaFe}_{11.6} \mathrm{Si}_{1.4}$ compound, an almost linear Arrott plot is observed with the absence of S-shaped curves with a negative slope confirming the occurrence of a second-order magnetic transition.

The magnetic entropy change $\left(\Delta S_{\mathrm{M}}\right)$ was calculated from the isothermal magnetization curves close to $T_{\mathrm{C}}$ using the Maxwell relation shown in Eq. (2) below:

$$
-\Delta S_{\mathrm{M}}=\int_{0}^{H}\left(\frac{\partial M}{\partial T}\right)_{H} \mathrm{~d} H .
$$

Previously, it has been shown both experimentally and theoretically that in compounds with first-order transitions displaying considerable hysteresis, the determination of $\Delta S_{\mathrm{M}}$ using the Maxwell relation is not reliable [14, 15].

Fig. $7-\Delta S_{\mathrm{M}}$ versus $T$ curve for the arc-melted and spark plasmasintered $\mathrm{LaFe}_{11.6} \mathrm{Si}_{1.4}$ compounds

The usual determination of $\Delta S_{\mathrm{M}}$ using magnetization data does not take into account magnetic irreversibility and usually results in erroneous spikes in the $\Delta S_{\mathrm{M}}$ estimations [16-19]. Recently, the origin of the spike has been attributed to the superheating of the FM state due to the magnetocaloric effect [20] or the alignment of magnetic domains [21]. $\Delta S_{\mathrm{M}}$ spikes have been observed in many materials such as MnAs [22], $\mathrm{MnAs}_{1-\mathrm{x}} \mathrm{Sb}_{\mathrm{x}}$ [23], $\mathrm{Gd}_{5}$ $\mathrm{Si}_{4-\mathrm{x}} \mathrm{Ge}_{\mathrm{x}}$ [24], $\mathrm{La}_{0.8} \mathrm{Ce}_{0.2} \mathrm{Fe}_{11.4} \mathrm{Si}_{1.6}$ [17, 25], $\mathrm{La}_{1-\mathrm{x}} \mathrm{Pr}_{\mathrm{x}-}$ $\mathrm{Fe}_{11.5} \mathrm{Si}_{1.5}$ [26], and $\mathrm{Mn}_{3} \mathrm{GaC}$ [27]. The appearance of the spike is due to the incorrect application of the Maxwell relation. Thus, the determination of $\Delta S_{\mathrm{M}}$ using magnetization data should be performed carefully.

Figure 7 shows the magnetic entropy change as a function of temperature for different increasing and decreasing magnetic field changes from 0 to $5 T$, for the arcmelted and SPS $\mathrm{LaFe}_{11.6} \mathrm{Si}_{1.4}$ compounds. A careful analysis of the $M-H$ curve for the arc-melted sample in Fig. 5 reveals that the $M-H$ curve measured at $T=T_{\mathrm{C}}=186 \mathrm{~K}$ 
exhibits a stepwise behavior. This stepwise behavior is an indication of the coexistence of the PM and FM states [26]. Interestingly, the calculated $\Delta S_{M}$ (using increasing field) for the arc-melted $\mathrm{LaFe}_{11.6} \mathrm{Si}_{1.4}$ compound consists of a plateau with a huge spike at $186 \mathrm{~K}$, which is obviously erroneous. A similar spike was observed for $\mathrm{Mn}_{1-\mathrm{x}} \mathrm{Fe}_{\mathrm{x}} \mathrm{As}$, which was due to the inadequate application of the Maxwell relation in the presence of coexisting PM and FM phases [28]. However, the calculated $\Delta S_{M}$ (using decreasing field) consists of a plateau with an asymmetrical distribution which is centered at $T_{\mathrm{C}}=186 \mathrm{~K}$. The maximum values of $\Delta S_{M}$ are found to be $29.8 \mathrm{~J} \mathrm{~kg}^{-1} \mathrm{~K}^{-1}$ for an increasing field change of $0-5 T$ and $19.6 \mathrm{~J} \mathrm{~kg}^{-1} \mathrm{~K}^{-1}$ for a decreasing field change of $5-0 T$. For the spark plasmasintered $\mathrm{LaFe}_{11.6} \mathrm{Si}_{1.4}$ compound, the $-\Delta S_{\mathrm{M}}$ versus $T$ curve occurs over a wider temperature range compared to the arcmelted compound and the maximum value of $\Delta \mathrm{S}_{\mathrm{M}}$ is found to be $7.4 \mathrm{~J} \mathrm{~kg}^{-1} \mathrm{~K}^{-1}$ for both the increasing and decreasing field change of $5 T$. This result is expected since the $M-$ $H$ curves for the spark plasma-sintered $\mathrm{LaFe}_{11.6} \mathrm{Si}_{1.4}$ compound shown in Fig. 5 display a negligible magnetic hysteresis. This reduction in the $\Delta \mathrm{S}_{\mathrm{M}}$ for the spark plasmasintered $\mathrm{LaFe}_{11.6} \mathrm{Si}_{1.4}$ compound is inherently related to the absence of the metamagnetic behavior in this compound, and the difference in $\Delta S_{\mathrm{M}}$ of the arc-melted and spark plasma-sintered $\mathrm{LaFe}_{11.6} \mathrm{Si}_{1.4}$ compounds is attributed to the difference in the volume fraction of the $\mathrm{NaZn}_{13}$-type phase. Also, the peak position of $\Delta \mathrm{S}_{\mathrm{M}}$ shifts to a higher temperature range due to the increase of $T_{\mathrm{C}}$ in the spark plasma-sintered $\mathrm{LaFe}_{11.6} \mathrm{Si}_{1.4}$ compound.

The efficiency of the arc-melted and spark plasma-sintered $\mathrm{LaFe}_{11.6} \mathrm{Si}_{1.4}$ compounds based on the magnetic entropy change is quantified by the relative cooling power (RCP), using Eq. (3) below:

$\mathrm{RCP}=-\Delta S_{\mathrm{M}} \times \partial T_{\mathrm{FWHM}}$

where $\partial T_{\text {FWHM }}$ is the width at half maximum obtained from the temperatures at half the maximum peak value of the $\Delta S_{\mathrm{M}}$ versus $T$ curve. The effective relative cooling power, $\mathrm{RCP}_{\text {eff }}$, is then obtained by subtracting the hysteresis loss from the relative cooling power. The obtained $\mathrm{RCP}_{\text {eff }}$ values for the arc-melted and spark plasma-sintered $\mathrm{LaFe}_{11.6} \mathrm{Si}_{1.4}$ compounds are then plotted as a function of the magnetic field and are shown in Fig. 8. For both samples, the $\mathrm{RCP}_{\text {eff }}$ was found to increase with an increase in the applied magnetic field and displaying values of 360 and $288 \mathrm{Jkg}^{-1}$ at $5 T$, for the arc-melted and spark plasmasintered $\mathrm{LaFe}_{11.6} \mathrm{Si}_{1.4}$ compounds, respectively. These values correspond to 88 and $70 \%$ to that observed of Gd. It is also worth noting that at low fields $(<2 T)$ the $\mathrm{RCP}_{\text {eff }}$ values of the arc-melted and spark plasma-sintered $\mathrm{LaFe}_{11.6} \mathrm{Si}_{1.4}$ compounds are comparable.

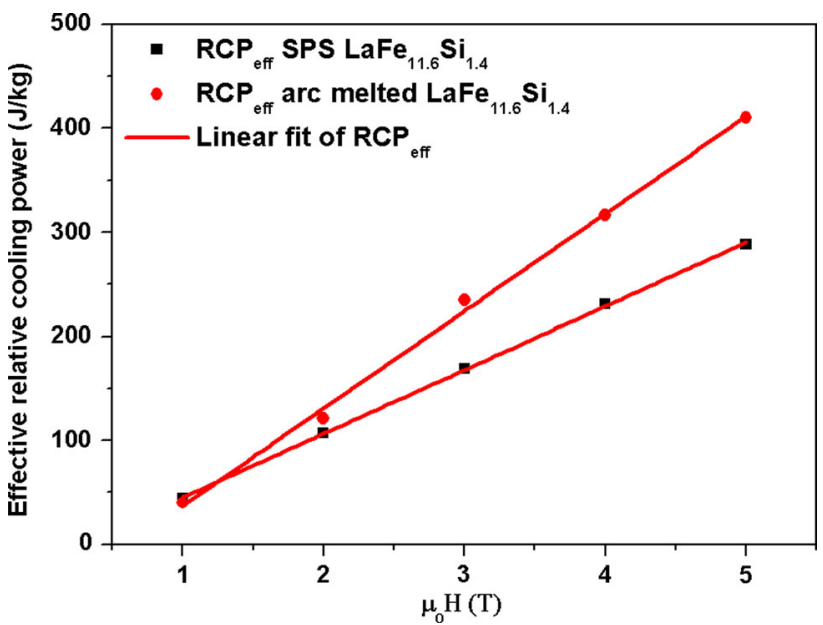

Fig. 8 Field dependencies of the effective relative cooling power $\mathrm{RCP}_{\text {eff }}$, for arc-melted and spark plasma-sintered $\mathrm{LaFe}_{11.6} \mathrm{Si}_{1.4}$ compounds

Table 2 lists the magnetocaloric properties of arc-melted and spark plasma-sintered $\mathrm{La}\left(\mathrm{Fe}_{\mathrm{x}} \mathrm{Si}_{1-\mathrm{x}}\right)_{13}$ compounds as well as other benchmark magnetocaloric materials for the purpose of comparison. Table 2 shows that there is a significant difference in the magnetocaloric properties of the spark plasma-sintered $\mathrm{LaFe}_{11.6} \mathrm{Si}_{1.4}$ compound from the present work to the $\mathrm{La}\left(\mathrm{Fe}_{\mathrm{x}} \mathrm{Si}_{1-\mathrm{x}}\right)_{13}$ alloy synthesized by Patissier et al. The differences observed in the magnetocaloric properties can be attributed to the differences in composition and the preparation methods. It is important to point out that in the synthesizing the $\mathrm{La}\left(\mathrm{Fe}_{\mathrm{x}} \mathrm{Si}_{1-\mathrm{x}}\right)_{13}$ alloy, Patissier et al. ball milled the starting powders for $1 \mathrm{~h}$ before sintering whereas in our work, we used a speedmixer to mix the starting powders for about $20 \mathrm{~min}$. It is probable that this longer ball milling time decreased the particle size of the starting powders which effectively enhanced the formation of the 1:13 phase during sintering, consequently enhancing the magnetocaloric properties of the $\mathrm{La}\left(\mathrm{Fe}_{\mathrm{x}} \mathrm{Si}_{1-\mathrm{x}}\right)_{13}$ alloy. The arc-melted $\mathrm{LaFe}_{11.6} \mathrm{Si}_{1.4}$ compound from the present work exhibits a significantly higher $\mathrm{RCP}_{\text {eff }}$ compared to other arc-melted $\mathrm{LaFe}_{11.6} \mathrm{Si}_{1.4}$ compounds documented in the literature as well as the spark plasma-sintered $\mathrm{LaFe}_{11.6} \mathrm{Si}_{1.4}$ compound from this work $^{28}$. It is also important to note that the spark plasmasintered $\mathrm{LaFe}_{11.6} \mathrm{Si}_{1.4}$ compound from this work displays a significantly higher $\mathrm{RCP}_{\text {eff }}$ compared to arc-melted $\mathrm{La}_{0.8-}$ $\mathrm{Gd}_{0.2} \mathrm{Fe}_{11.4} \mathrm{Si}_{1.6} \mathrm{~B}_{0.3}$ compound. Therefore, our results demonstrate that the spark plasma-sintered $\mathrm{LaFe}_{11.6} \mathrm{Si}_{1.4}$ compound is a potential candidate for use in magnetic refrigeration, especially at low fields, making it ideal for use in magnetic refrigeration as it could operate efficiently in a magnetic field provided by permanent magnets. It also has the added advantage of being synthesized quickly at 
Table 2 MCE properties of benchmark magnetocaloric materials

\begin{tabular}{|c|c|c|c|c|}
\hline Material & Order of transition & $T_{\mathrm{C}}(\mathrm{K})$ & $\mathrm{AS}_{\mathrm{M}}(5 T)(\mathrm{J} / \mathrm{kg} \mathrm{K})$ & $\operatorname{RCP}(5 T)(\mathrm{J} / \mathrm{kg})$ \\
\hline SPS $\mathrm{LaFe}_{11.4} \mathrm{Si}_{1.6}[11]$ & Second & 219 & 10.6 & - \\
\hline Arc-melted Gd [29] & Second & 294 & 10.2 & 410 \\
\hline Arc-melted $\mathrm{LaFe}_{11.4} \mathrm{Si}_{1.6}[30]$ & First & 195 & 18 & 324 \\
\hline Arc-melted $\mathrm{La}_{0.8} \mathrm{Gd}_{0.2} \mathrm{Fe}_{11.4} \mathrm{Si}_{1.6} \mathrm{~B}_{0.3}$ [31] & Second & 222 & 6.6 & 245 \\
\hline $\mathrm{SPS} \mathrm{LaFe}_{11.6} \mathrm{Si}_{1.4}$ (this work) & Second & 230 & 7.4 & 288 \\
\hline Arc-melted $\mathrm{LaFe}_{11.6} \mathrm{Si}_{1.4}$ (this work) & First & 186 & 30 & 360 \\
\hline
\end{tabular}

relative low temperatures, thus decreasing the energy consumption necessary to prepare the material making it a cheaper processing option for the magnetocaloric components. Also the second-order nature of the phase transition of the spark plasma-sintered $\mathrm{LaFe}_{11.6} \mathrm{Si}_{1.4}$ compound eliminates hysteretic losses which are detrimental to the cooling capacity of this material system.

\section{Conclusions}

Spark plasma sintering of the $\mathrm{LaFe}_{11.6} \mathrm{Si}_{1.4}$ alloys has been investigated in this work. Using this method, the heat treatment times required to yield or obtain the 1:13 phase was drastically reduced from 14 days to 30 min making SPS a quicker and cheaper way of synthesizing these alloys, consequently presenting advantages in terms of energy consumption. Reducing the cost of synthesizing these alloys will have a positive impact on the affordability of $\mathrm{LaFe}_{11.6} \mathrm{Si}_{1.4}$ alloy-based magnetic refrigerators.

The main conclusions of this work are as follows: (1) The MCE of SPS $\mathrm{LaFe}_{11.6} \mathrm{Si}_{1.4}$ alloys is lower than the MCE reported for benchmark magnetocalorics such as Gd and $\mathrm{Gd}_{5} \mathrm{Si}_{2} \mathrm{Ge}_{2}$ at $5 T$ but competitive at $2 T$, as shown in Table 2. (2) The SPS $\mathrm{LaFe}_{11.6} \mathrm{Si}_{1.4}$ alloys require a short heat treatment time of $30 \mathrm{~min}$, thus making its synthesis cost effective.

Also a broader working temperature range of the MCE is obtained in the SPS $\mathrm{LaFe}_{11.6} \mathrm{Si}_{1.4}$ alloy as compared to the arc-melted $\mathrm{LaFe}_{11.6} \mathrm{Si}_{1.4}$ alloy. In the SPS $\mathrm{LaFe}_{11.6}$ $\mathrm{Si}_{1.4}$ alloy, the order of transition is shifted to second order eliminating both thermal and magnetic hysteresis. In this work, we have also shown that in the field range, $0-2 T$, the relative cooling power of the SPS $\mathrm{LaFe}_{11.6} \mathrm{Si}_{1.4}$ alloy is competitive with the arc-melted $\mathrm{LaFe}_{11.6} \mathrm{Si}_{1.4}$ alloy. We are currently exploring various methods (such as varying particle size of starting powders and heat treatment investigations) to significantly increase the amount of $1: 13$ phase in our SPS $\mathrm{LaFe}_{11.6} \mathrm{Si}_{1.4}$ alloys, and if these efforts prove successful, they will be reported in due course.
Acknowledgments This research was funded from the Engineering and Physical Sciences Research Council (EPSRC) (Grant Number L017563). Professor Damian Hampshire and Dr Mark Raine (Physics Department, Durham University) are gratefully acknowledged for help with the magnetic measurements.

Open Access This article is distributed under the terms of the Creative Commons Attribution 4.0 International License (http://crea tivecommons.org/licenses/by/4.0/), which permits unrestricted use, distribution, and reproduction in any medium, provided you give appropriate credit to the original author(s) and the source, provide a link to the Creative Commons license, and indicate if changes were made.

\section{References}

1. K.A. Gschneidner Jr., V.K. Pecharsky, A.O. Tsokol, Rep. Prog. Phys. 68, 1479 (2005)

2. A.M. Tishin, Y.I. Spichkin, Series in Condensed Matter (IOP, London, 2003)

3. H. Wada, Y. Tanabe, Appl. Phys. Lett. 79, 3302 (2001)

4. B. Li, J. Du, W.J. Ren, W.J. Hu, Q. Zhang, D. Li, Z.D. Zhang, Appl. Phys. Lett. 92, 242504 (2008)

5. A.K. Pathak, P. Basnyat, I. Dubenko, S. Stadler, N. Ali, J. Magn. Magn. Mater. 322, 692 (2010)

6. V. Raghavan, J. Phase Equilib. 22, 158 (2001)

7. R. Yamanoglu, W. Bradbury, E.A. Olevsky, R.M. German, Met. Mater. Int. 19, 1029 (2013)

8. T. Murakami, A. Kitahara, Y. Koga, M. Kawahara, H. Inui, M. Yamaguchi, Mater. Sci. Eng. A 239, 672 (1997)

9. I.R. Idza, M. Hashim, N. Rodziah, I. Ismayadi, A.R. Norailiana, Mater. Res. Bull. 47, 1345 (2012)

10. H. Tsuji, A.T. Saito, T. Kobayashi, S. Sakurada, International Cryocooler Conference (Inc, Boulder, 2007)

11. A. Patissier, V. Paul-Boncour, J. Alloys Compd. 645, 143 (2015)

12. S.B. Roy, P. Chaddah, V.K. Percharsky, K.A. Gschneider Jr., Acta Mater. 56, 5895 (2008)

13. J. Inoue, M. Shimizu, J. Phys. F: Met. Phys. 12, 1811 (1982)

14. A. Giguere, M. Foldeaki, B.R. Gopal, R. Chahine, T.K. Bose, A. Frydman, J.A. Barclay, Phys. Rev. Lett. 83, 2262 (1999)

15. R.P. Santana, N.A. de Oliveira, P.J. von Ranke, J. Alloys Compd. 509, 6346 (2011)

16. C. Xu, G.D. Li, L.G. Wang, J. Appl. Phys. 99, 123913 (1999)

17. P. Shamba, J.C. Debnath, J.L. Wang, S.J. Campbell, S.J. Kennedy, S.X. Dou, J. Appl. Phys. 109, 07A940 (2011)

18. Z. Lin, S. Li, M. Liu, J.G. Duh, K. Peng, X. Mao, J. Alloys Compd. 489, 1 (2010)

19. J.S. Amaral, V.S. Amaral, Appl. Phys. Lett. 94, 042506 (2009)

20. H.W. Zhang, J. Shen, Q.Y. Dong, T.Y. Zhao, Y.X. Li, J.R. Sun, B.G. Shen, J. Magn. Magn. Mater. 320, 1879 (2008) 
21. J.D. Zou, B.G. Shen, B. Gao, J. Shen, J.R. Sun, Adv. Mater. 21, 693 (2009)

22. L. Tocado, E. Palacios, R. Burriel, J. Appl. Phys. 105, 093918 (2009)

23. H. Wada, Y. Tanabe, Appl. Phys. Lett. 79, 3303 (2001)

24. J.D. Zou, Chin. Phys. B 21, 037503 (2012)

25. C. Xu, G.D. Li, L.G. Wang, J. Appl. Phys. 99, 123913 (2006)

26. G.J. Liu, R. Sun, J. Shen, B. Gao, H.W. Zhang, F.X. Hu, B.G. Shen, Appl. Phys. Lett. 90, 032507 (2007)

27. M.H. Yu, L.H. Lewis, A.R. Moodenbaugh, J. Magn. Magn. Mater. 299, 317 (2006)
28. M. Balli, D. Fruchart, D. Gignoux, R. Zach, Appl. Phys. Lett. 95, 072509 (2009)

29. E.C. Passamani, A.Y. Takeuchi, A.L. Alves, A.S. Demuner, E. Favre-Nicolin, C. Larica, J.R. Proveti, A.M. Gomes, J. Appl. Phys. 102, 093906 (2007)

30. A. Fujita, S. Fujieda, K. Fukamichi, H. Mitamura, T. Goto, Phys. Rev. B: Cond. Mat. 65, 014410 (2001)

31. P. Shamba, R. Zeng, J.L. Wang, S.J. Campbell, S.X. Dou, J. Magn. Magn. Mater. 331, 102 (2013) 